\title{
Military Medicine
}

Authors alone are responsible for opinions expressed in the contribution and for its clearance through their federal health agency, if required.

\section{Potential of Influenza Vaccine and Amantadine to Prevent Influenza A Illness in Canadian Forces Personnel 1980-1983}

\author{
Fred Y. Aoki, MD* \\ Daniel S. Sitar, PhD\$ \\ E. V. Milley, RNI \\ H. E. Hughes, RN \\ L. Sekla, MD** \\ T. Sheppard, $R N$
}

A randomized, placebo-controlled, single-blind trial was designed to compare the efficacy and side-effects of a standard influenza vaccine and amantadine chemoprophylaxis, to prevent influenza A virus illness in Canadian Forces Bases (CFB) personnel in Manitoba during three winter seasons from 1980-83. From 220 to 333 volunteers were allocated to vaccine $(V)$, saline injection as vaccine placebo (VP), amantadine $100 \mathrm{mg} /$ day (Al), $200 \mathrm{mg} /$ day (A2) or placebo (AP) capsule groups. A median of $89 \%$ of $V$ recipients had HAI titres > 20, 4-6 weeks after immunization, indicating protection against illness due to vaccine strains. Myalgia was the commonest side effect but was not clinically important.

Influenza A community outbreaks due to vaccine strains, or antigenically related ones, occurred in 1980-81 and 1982-83. Chemoprophylaxis was continued for 32 and 39 consecutive days, respectively, during those periods and was well tolerated. However, $16 \%$ of $\mathrm{A} 1$ or $\mathrm{A} 2$ recipients were noncompliant as evidenced by a lack of drug in urine or plasma. The incidences of laboratoryconfirmed illness were 3 and 13 per 1000 in these two years, too low to enable us to assess the efficacy of our preventative measures. Subclinical influenza occurred in $<10 \%$ of unimmunized subjects.

These data suggested that both strategies for preventing influenza in CFB personnel had the potential to be protective with minimal adverse effects. However, our data did not permit us to recommend one in preference to the other.

Supported by grants from the National Health Research and Development Program of Canada (number 6607-1207-54) and The Canadian Foundation for the Advancement of Clinical Pharmacology.

* Associate Professor of Medicine, Medical Microbiology, Pharmacology \& Therapeutics.

† Current Address: Department of Medicine, University of British Columbia, Vancouver, B.C.

₹ Associate Prof essor of Medicine \& Medical Microbiology.

$\$$ Associate Professor of Medicine, Pharmacology and Therapeutics.

\| Assistant Professor of Medicine \& Medical Microbiology.

I Research Assistants, Department of Medical Microbiology, University of Manitoba, Winnipeg, Manitoba.

* Assistant Director, Cadham Provincial Laboratory, Winnipeg, Manitoba.

it Research Assistants, Canadian Forces Medical Services, Winnipeg, Manitoba.

¥¥M.R.C. Common Cold Unit, Salisbury, England

\author{
H. Grant Stiverł‡ \\ Gregory W. Hammond, $M D \|$ \\ C. Vermeersch, RNT \\ T. Cooper, $R N \Phi$ \\ M. Lamontage, RNt† \\ K. Callow, RT‡¥
}

Introduction

Tnfluenza A virus infection epidemics are associated with Isignificant morbidity and mortality. ${ }^{1}$ Preventive measures have depended upon immunization with vaccine, but this strategy is not an uncomplicated one. To be optimally effective the vaccine must be antigenically closely related to the epidemic virus strain. Such vaccines have decreased influenza attack rates by $60-70 \% .^{2}$ The phenomena of antigenic shift and antigenic drift have necessitated continuous production of new vaccines to protect against epidemic strains. Moreover, the occurrence of Guillan-Barre Syndrome complicating widespread vaccination against influenza $\mathrm{A} / \mathrm{New}$ Jersey/8/76 in 1976, has further demonstrated the potential problems that can arise from the use of vaccine for influenza prophylaxis.

Amantadine $\mathrm{HCl}$ (Symmetrel(B)) is currently licensed for influenza A prophylaxis. A dose of $100 \mathrm{mg}$ ingested twice daily has been shown to consistently produce protection against natural and induced influenza A illness of about $75 \%$ compared to placebo. ${ }^{3}$ This dose is generally very well tolerated for extended periods of time in healthy adults. The drug inhibits all types of influenza A viruses in vitro. ${ }^{3}$ Therefore, its efficacy ought not be affected by antigenic shift or drift. Thus, it theoretically is a suitable alternative to vaccine.

The data of Smorodintsev et al suggested that amantadine, $100 \mathrm{mg}$ once daily, might be as efficacious as the recommended $200 \mathrm{mg}$ daily dose. ${ }^{4}$ A study of amantadine dose-plasma concentration-effect relationships during prophylaxis of experimental influenza $A$ infection with attenuated virus in young adult volunteers, provided some support for this hypothesis. ${ }^{5}$ These data suggested that doses less than $200 \mathrm{mg} /$ day may be as efficacious and that their efficacy warranted further investigation against natural influenza $\mathrm{A}$ infections.

Successful chemoprophylaxis with amantadine would require that the drug be available rapidly if and when epidemic influenza A occurred, with subjects ingesting drug until the epidemic subsided. This approach has been demonstrated to be practicable in college students ${ }^{6}$ and families. ${ }^{7}$ The relative 
merits of the two strategies have never been studied in parallel. This study aimed to test the hypothesis that vaccine and amantadine in both 100 and $200 \mathrm{mg}$ daily doses are not different for the prevention of influenza A infection. A prospective, placebo-controlled, randomized study was undertaken in $\mathrm{Ca}$ nadian Forces personnel to evaluate the efficacy and sideeffects of immunization compared to prophylaxis with amantadine initiated only when influenza A was identified in the Province of Manitoba. The investigation was conducted from November to April during three successive years, 1980-83, employing a single-blind design in which subjects were unaware of whether they had been injected with vaccine or placebo, or whether the daily amantadine dose to which they had been allocated was $100 \mathrm{mg}, 200 \mathrm{mg}$ or 0 (placebo).

\section{Materials and Methods}

Study population. Healthy men and women who gave written, informed consent were enrolled at Canadian Forces Bases (C.F.B.) Winnipeg, Shilo, Portage and at Number 2 Battalion, Princess Patricia Canadian Light Infantry. Volunteers were allocated to one of five experimental groups, using a computergenerated list of random numbers: influenza vaccine (V), placebo vaccine (VP), amantadine $100 \mathrm{mg} /$ day (Al), $200 \mathrm{mg} /$ day (A2) or amantadine placebo (AP).

For the 1981-82 study, volunteers were randomly allocated after stratification according to age $<28$ years and $>29$ years, since two doses of vaccine were recommended by the manufacturer for persons $<28$ years and one dose for those $>29$ years.

Pregnant women were excluded. Flight crew were also excluded because of the unknown effect of amantadine on ability to fly aircraft.

Study design. We calculated sample sizes needed to demonstrate a difference $\geq 25 \%$ between amantadine and vaccine with a power $=0.8$ and $P \leq 0.05$ for a 2 -tailed test, as such a difference was considered to be a clinically important one. We assumed that illness rates would be $30 \%$ during an influenza A epidemic and that at least one modality would be $70 \%$ effective in preventing illness. Sample sizes of 57 per group were calculated to be necessary, for a total of 285 per year.

Vaccine and vaccine placebo. Inactivated whole virus polyvalent influenza $A$ and $B$ vaccines were administered as recommended by the manufacturer, Connaught Laboratories, Toronto, Ontario. The vaccines used in all years contained the same influenza strains: A/Brazil/11/78 (H1 Nl), A/Bangkok/ 1/79 (H3N2) and B/Singapore/222/79. Each $0.5 \mathrm{ml}$ dose of the 1980-81 vaccine contained $7 \mu \mathrm{g}$ of hemagglutinin (HA) of each virus strain, whereas each $0.5 \mathrm{ml}$ dose of the vaccines used in the last two years of the study contained $15 \mu \mathrm{g}$ of $\mathrm{HA}$ of each virus strain. In 1980-81, each V subject was injected intramuscularly with $0.5 \mathrm{ml}$. In $1981-82$, subjects $\leq 28$ years were given two injections of $0.5 \mathrm{ml} 4$ weeks apart, and those $>29$ years, one injection of $0.5 \mathrm{ml}$, all subcutaneously. In $1982-83$, all $\mathrm{V}$ subjects were injected with $0.5 \mathrm{ml}$ subcutaneously. Sterile saline was used as vaccine placebo. All injections were in the left deltoid area.

Amantadine and amantadine placebo. Amantadine $\mathrm{HCl}$ and indistinguishable placebo capsules were supplied to the three chemoprophylaxis groups during the 1980-81 and 1982-83 study periods but not in 1981-82, as no outbreak of influenza A infection occurred that year. In 1980-81, medication was provided as six-week supplies of single daily dose bottles each containing two capsules, comprising either one amantadine plus one placebo (100 $\mathrm{mg} /$ day), two amantadine capsules (200 mg/day) or two placebo capsules. In the $1982-$ 83 season, six-week supplies were provided in two bottles. One contained amantadine and the other placebo (100 $\mathrm{mg} /$ day), both contained amantadine (200 $\mathrm{mg} /$ day), or both contained placebo. Subjects were instructed to take one capsule from each bottle each day.

Amantadine or placebo capsules were distributed only when the Cadham Provincial Laboratory confirmed that influenza A illness was occurring in Manitoba.

Amantadine concentrations in plasma and urine. Amantadine concentrations in plasma were measured as described. ${ }^{8}$ Urine was tested after initial 1:1000 dilution in sterile distilled water. All assays were done in duplicate and agreed within \pm $10 \%$. The technician doing the assay was unaware of the dose of drug being ingested by the donor of the plasma or urine sample. The assay was linear from 10 to $1000 \mathrm{ng} / \mathrm{ml}$.

The presence of amantadine in urine or plasma was used to assess compliance. Urine and plasma samples were collected without prior notice for this purpose in 1980-81 and 198283 , respectively.

Serum hemagglutination inhibiting (HAI) antibody titres. Serum samples were obtained prior to initiation of the study and at 4-6 week intervals thereafter and during the acute phase of any respiratory tract illness and 2-3 weeks thereafter. HAI titres were measured using the standard CDC/USPHS method after inactivation of non-specific inhibitors by receptor destroying enzyme and included appropriate controls. ${ }^{9}$ Antigens used included vaccine strains plus those causing illness in Manitoba during a study period. In 1982-83, these included A/Philippines/2/82 (H3N2) and A/Oregon/4/80 (H3N2).

Susceptibility was defined as an HAI titre $\leq 20$ to the homologous virus. Seroconversion or a significant rise was defined as a $\geq 4$-fold increase in titre. For calculation of geometric mean titre (GMT), HAI titres were transformed logarithmically to base 10 ; titres of $<10$ were arbitrarily treated as transformed values of 0 .

Adverse symptoms. Adverse symptoms were assessed from questionnaires completed for 10 consecutive days after injections and the start of each 3-week period of capsule ingestion. The questionnaire listed 25 symptoms or queries including 2 relating to overall well being (generally well, unwell), 7 relating to respiratory tract infections (fever, cough, headache, sore muscles, stuffed nose, running nose, and sore throat; fever, headache, and sore muscles were also expected to reflect adverse reactions to vaccine), 4 relating to gastrointestinal function (normal appetite, nausea, diarrhea, abdominal pain), 11 relating to central nervous system function (sleepiness, insomnia, nightmares, dizziness, difficulty concentrating, difficulty remembering, irritable, dull, nervous, "hyper" or depressed), and urinary frequency.

Respiratory tract illness. The following definitions were used to classify acute intercurrent respiratory tract illnesses in 1981-82 and 1982-83: 
a) Common cold-like illness. Prominent nasal symptoms in the absence of serious constitutional upset. Coryza plus nasal stuffiness or obstruction required for diagnosis.

b) Influenza-like. Abrupt onset of constitutional symptoms. Diagnosis required three of: chilliness or a chill, fever, headache, myalgia or cough.

c) Pharyngitis. Fever with sore throat with or without constitutional upset.

d) Laryngitis and/or tracheitis and/or bronchitis. Hoarseness or loss of voice or harsh cough with or without sputum.

e) Pneumonia. Diagnosis required one or more of dyspnea, cough, sputum, pleuritic chest pain plus a chest X-ray showing infiltrates compatible with the diagnosis.

Volunteers were asked to notify the study nurses within 24 hours of onset of symptoms. Nurses classified the illness and obtained swab specimens of nose and throat secretions and acute and convalescent blood samples. Secretions were cultured for viruses using 10-day embryonated chicken eggs and primary rhesus monkey kidney cell cultures and acute and convalescent HAI titres were determined for prevalent influenza strains. Serum samples collected in 1981-82 and 198283 were also tested for seroconversion to coronaviruses strains $229 \mathrm{E}$ and 0C43 using an ELISA assay modified from that of Kraaijeveld et al. ${ }^{10}$ Seroconversion using the ELISA technique was diagnosed when the ratio of optical density in convalescent:acute serum specimens was $\geq 1.5$.

Analyses. GMT data between groups were considered to be significantly different when the difference was $\geq 4$-fold. Other differences between groups were compared by $\mathrm{X}^{2}$-tests unless otherwise specified. Differences with $\mathrm{P} \leq 0.05$ for 2 -tails were considered significant.

\section{Results}

In the 3 study years, 346, 220 and 250 volunteers respectively were enrolled. In 1981-82 and 1982-83, it was apparent that the total number of volunteers would be less than the number desired, 285. Accordingly, allocation was altered so that the number of VP and AP volunteers would be one-half of that in V, A1 \& A2 groups. No V or VP subjects withdrew. In $1980-81,13$ (3.8\%) withdrew; in 1981-82, 0; and in 1982$83,24(9.6 \%)$ subjects withdrew from chemoprophylaxis groups. The frequency of withdrawal was not related to amantadine dose. Thus, subsequent analyses were undertaken on the number of subjects in Table 1. Only 6-8 individuals in

TABLE 1

NUMBER OF CANADIAN FORCES PERSONNEL ALLOCATED TO RECEIVE INFLUENZA VACCINE, VACCINE PLACEBO OR AMANTADINE 100 OR 200 MG/DAY OR PLACEBO TO PREVENT INFLUENZA A ILLNESS IN THE WINTERS OF 1980-83 INCLUSIVE

\begin{tabular}{lcccc} 
& \multicolumn{4}{c}{$1981-1982$} \\
\end{tabular}

TABLE 2

SERUM GEOMETRIC MEAN TITRES (GMT) TO INFLUENZA VACCINE HEMAGGLUTININS IN CANADIAN FORCES PERSONNEL 1980-83, AT THE START OF EACH STUDY PERIOD (PRE) AND 4-6 WEEKS LATER (AFTER V GROUP RECEIVED VACCINE). PERCENT OF SUBJECTS SEROCONVERTING OR DEVELOPING $\geq 4$-FOLD RISES IN HAI TITRES IN BRACKETS

\begin{tabular}{|c|c|c|c|c|c|c|}
\hline & \multicolumn{6}{|c|}{ Geometric mean HAI titres in } \\
\hline & \multicolumn{2}{|c|}{$1980-1981$} & \multicolumn{2}{|c|}{$1981-1982$} & \multicolumn{2}{|c|}{$1982-1983$} \\
\hline & Pre & 4-6 weeks & Pre & 4-6 weeks & Pre & 4-6 weeks \\
\hline \multicolumn{7}{|c|}{ A/Bangkok/1/79 } \\
\hline V Group & 2 & $41(85)$ & 9 & $64(63)$ & 13 & $100(100)$ \\
\hline All others & 2 & $2(8)$ & 6 & $5(0)$ & 16 & $25(7)$ \\
\hline \multicolumn{7}{|c|}{ A/Brazil/11/78 } \\
\hline V Group & $N A^{*}$ & NA & 13 & $59(53)$ & 20 & $110(48)$ \\
\hline All others & $5 \dagger$ & $5(5)^{+}$ & 6 & $6(1)$ & 15 & $15(0)$ \\
\hline \multicolumn{7}{|c|}{ B/Singapore/222/79 } \\
\hline$V$ group & NA & NA & 6 & $29(54)$ & 15 & $70(58)$ \\
\hline All others & $4 \dagger$ & $4(0)^{\dagger}$ & 5 & $4(1)$ & 15 & $14(0)$ \\
\hline
\end{tabular}

- $\mathrm{NA}=$ not available.

$\dagger=$ groups VP and AP only.

each study year had been immunized against influenza in previous years.

Subjects withdrew because of adverse drug reactions (ADR), for reasons not related to medication (non-ADR), and for unknown reasons: 2,4 , and 7 subjects respectively, withdrew for these reasons in $1980-81$ and 8,15 , and 1 , in 1982-83. These proportions were not different between years. The ADR's prompting withdrawal in 1980-81, included difficulty remembering and concentrating ( 1 subject $\mathrm{Al}$ group) and acid indigestion (1, AP); in 1982-83, headache with sore scalp (1 subject, Al group), dizziness with a "hyper" sensation, anxiety and insomnia (4), nausea (1), sleepiness (1), (all 6 in A2 group) and sleepiness (1, AP group). There was no relationship to amantadine dose. The non-ADR's included pregnancy, concurrent respiratory illness, lack of interest, development of a peptic ulcer, inability to swallow capsules, and left Forces. The proportions of subjects withdrawing in each dose group due to ADR or non-ADR in either year or between years were not different.

Influenza A infection was confirmed in Manitoba during the winters of $1980-81$ and $1982-83 .^{11.12}$ In $1980-81$, influenza A/Bangkok/1/79 (H3N2)-like strains and A/Brazil/11/78 (H1N1) were isolated. Chemoprophylaxis was started December 10 and continued until January 18 , at which time influenza $A$ viruses were no longer being isolated at the Cadham Provincial Laboratory. In 1982-83, influenza was due to A/Oregon/4/80 (H3N2)-like, A/Phillipines/2/82 (H3N2)-like, and A/Brazil/ 11/78 (H3N2)-like strains (Dr. A. P. Kendal, WHO Influenza Laboratory, CDC, Atlanta, Georgia; personal communication). Chemoprophylaxis was started December 14 and continued until January 15.

Pre-study and 4-6 weeks influenza A and B HAI GMT in the $\mathrm{V}$ groups and in the unimmunized groups are presented in Table 2. Data for subjects $\leq 28$ years and $>29$ years in 198182 were not different and were therefore combined. GMT for the unimmunized groups in each year were not different from the $V$ group or each other; for clarity, results for the unimmunized groups were also combined. Susceptibility to the vaccine viruses declined over the 3 years. All individuals in 1980-81 were susceptible to A/Bangkok/1/79. A median of $89 \%$ (range 
$80-97 \%$ ) of subjects in the five experimental groups were susceptible in 1981-82, a decline since the previous year $(\mathrm{P}<$ $0.001)$. In $1982-83$, a median of $56 \%(52-92 \%)$ of subjects in groups were susceptible $(\mathrm{P}<0.001$ compared to $1980-81$ and 1981-82). For A/Brazil/11/78, the median (range) percentages of susceptible subjects in treatment groups in 1980-81, 198182 and $1981-83$ were $81 \%(69-92 \%), 87 \%(76-91 \%)$ and $61 \%(57-69 \%)$, respectively. Susceptibility to A/Brazil/11/78 declined between 1981-82 and 1982-83 (P<0.001). For B/ Singapore/222/79, median (range) percentages of susceptible subjects in groups were $93 \%(91-94 \%)$. 91\% (89-97\%) and $67 \%(61-76 \%)$. Susceptibility to B/Singapore/222/79 declined between $1981-82$ and $1982-83(\mathrm{P}<0.001)$. Titres $>20$ and $>40$ to $\mathrm{A} /$ Oregon/4/80 were observed in pre-study sera in $94 \%$ and $72 \%$ of subjects respectively in 1982-83; $100 \%$ of subjects had titres $>40$ to $\mathrm{A} /$ Philippines $/ 2 / 82$ that year.

The incidence of clinical and subclinical influenza infection (Table 2) in our study population was $<10 \%$. Acute influenza A illnesses were confirmed in one subject due to $\mathrm{A} / \mathrm{Brazil} / \mathrm{I} 1 /$ 78 in 1980-81, none in 1981-82 and two individuals to $\mathrm{A} /$ Bangkok/1/79 in 1982-83. Subclinical influenza A/Bangkok/ $1 / 79$ infection was demonstrated at $8 \%, 0$ and $7 \%$ of unimmunized volunteers in 1980-81, 1981-82 and 1982-83, respectively. For influenza $\mathrm{A} / \mathrm{Brazil} / 11 / 78$, the results were $5 \%$, $1 \%$ and 0 , respectively, and incidentally, for B/Singapore/ $222 / 79,0,1$, and $0 \%$. There were no significant differences in subclinical influenza A or B attack rates between unimmunized groups in each year or between results based on HAI titres at 4-6 weeks or at the end of the study. In 1982-83, subclinical infection with $\mathrm{A} /$ Oregon/4/80 and $\mathrm{A} /$ Philippines/ $2 / 82$ occurred in $0-10 \%$ for the two viruses respectively, in the unimmunized groups.

In the $\mathrm{V}$ groups, GMT for all vaccine HA rose significantly 4-6 weeks after immunization (Table 2). Seroconversion or a significant rise in HAI titre was demonstrated in $48-100 \%$ of subjects. Pre-existing (titre $\geq 10$ ) homologous antibodies to A/ Brazil/1/78 and B/Singapore/222/79 but not A/Bangkok/1/ 79 were associated with fewer $\geq 4$-fold, rises at $4-6$ weeks compared to seroconversion rates in seronegative subjects $(P$ $<0.01$ for A/Brazil/1/78 and $\mathrm{P}<0.001$ for B/Singapore/ $222 / 79$ ). There was no difference in the proportion of subjects responding to A/Bangkok/1/79 in 1980-81 (7 $\mu \mathrm{g}$ HA per dose) than in 1981-82 or 1982-83 (15 $\mu \mathrm{g}$ HA per dose), regardless of the pre-immunization titre of homologous HAI antibody. As well, the GMT detected at 4-6 weeks with the $7 \mu$ g HA vaccine in seronegative subjects was not less than with $15 \mu \mathrm{g} \mathrm{HA}$.

At 4-6 weeks, $89 \%$ of all V subjects had HAI titres $>20$ for all 3 vaccine HA during all 3 years: $33 \%$ had titres $>40$. After 5-6 months, GMT's had not fallen significantly from those seen at 4-6 weeks. The decline ranged from 0.7 to 1.3 (median 0.8 ) for the three vaccine HA over each of the three study years.

Ill Volunteers. The incidence of acute respiratory tract infection was 60 per 1000 subjects in $1980-81$ and 277 per 1000 in both 1981-82 and 1982-83. The percentages of all subjects developing an acute respiratory tract illness were greater in the last two years of the study than in the first year, increasing from $6.0 \%$ in $1980-81$, to $27.7 \%$ and $27.8 \%$ in the last two years $(\mathrm{P}<0.001)$. The percentages of subjects in the five experimental groups in each year, developing acute respiratory tract illnesses, were not different. Classification of the illnesses in the last two years of the study showed no differences in the proportions of subjects in different groups each year developing different types of acute respiratory tract infection.

Virus was isolated from nose and throat secretions of $2 / 63$ subjects tested in the last year and none of the 20 and 61 subjects tested in the first and second year respectively. The virus isolates were a parainfluenza 3 virus from one subject with a common cold-like illness and an influenza A/Bangkok/ $1 / 79$ virus from an immunized subject with an influenza-like illness with homologous pre- and post-vaccine titres $>320$. An etiologic diagnosis was established by serologic testing in 1 / $15,12 / 61$ and $27 / 63$ individuals in the three successive study years (Table 3). In 1980-81, one unimmunized subject seroconverted to A/Brazil/11/78. In all 5 subjects who had laryngotracheobronchitis (3 in 1981-82) and the one individual with pneumonia (1982-83), serologic tests were non-diagnostic.

Compliance. Compliance was evaluated once during the 39 and 32 day periods in $1980-81$ and $1982-83$, respectively. In 1980-81, urine samples were collected from $43(58 \%) \mathrm{A} 1$ recipients, $48(65 \%) \mathrm{A} 2$ recipients and $32(67 \%)$ AP recipients. These percentages were not different. Assay for amantadine revealed none in all 32 placebo recipients, $4(10 \%) \mathrm{A} 1$ subjects

TABLE 3

CAUSES OF ACUTE RESPIRATORY TRACT ILLNESS DIAGNOSED BY SEROLOGIC TESTING

\begin{tabular}{|c|c|c|c|c|c|c|c|c|}
\hline & \multicolumn{2}{|c|}{$\begin{array}{c}\text { Coronavirus } \\
\text { Types }\end{array}$} & \multicolumn{3}{|c|}{$\begin{array}{c}\text { Parainfluenza } \\
\text { Types }\end{array}$} & \multirow{2}{*}{$\begin{array}{l}\text { M. pneu- } \\
\text { moniae }\end{array}$} & \multirow{2}{*}{$\begin{array}{l}\text { Respiratory } \\
\text { Syncytial } \\
\text { Virus } \\
\end{array}$} & \multirow{2}{*}{$\begin{array}{c}\text { Influenza } \\
\text { A/Bangkok/1/ } \\
79 \\
\end{array}$} \\
\hline & $\mathrm{OC} 43$ & $229 \mathrm{E}$ & 1 & 2 & 3 & & & \\
\hline \multicolumn{9}{|l|}{ Common cold } \\
\hline $1981-82(34 \dagger)$ & 6 & & $2^{*}$ & $2^{*}$ & & 1 & & \\
\hline $1982-83(34)$ & $3+1 *+*$ & $1^{*}$ & & & 2 & & $3+1^{* *}$ & 2 \\
\hline \multicolumn{9}{|l|}{ Influenza-like } \\
\hline $1981-82(16)$ & $1 *$ & 1 & $1^{*}$ & & $1^{*}$ & 1 & & \\
\hline $1982-83(13)$ & 2 & 4 & & & & & & \\
\hline \multicolumn{9}{|l|}{ Pharyngitis } \\
\hline $1981-82(7)$ & & 1 & & & & & & \\
\hline $1982-83(14)$ & 3 & 2 & & & 1 & 1 & 2 & \\
\hline
\end{tabular}

$r=$ number of subjects studied.

$:{ }^{* *}=$ denote same individual. 
and $6(13 \%)$ A2 group subjects. Compliance between Al and A2 subjects was not different. The amantadine concentrations in the urine in $\mathrm{Al}$ recipients was $49.3 \pm 5.9 \mu \mathrm{g} / \mathrm{ml}$ (mean \pm $\mathrm{SE}$ ), significantly less than that in A2 recipients, $146.6 \pm 22.1$ $\mu \mathrm{g} / \mathrm{ml}$ (Mann-Whitney U test, $\mathrm{P}<0.001$ ).

In 1982-83, plasma samples were collected from $43(94 \%)$ A1 recipients, 44 (98\%) A2 recipients and 30 (91\%) AP recipients, percentages that were not different. No amantadine was present in all AP, $9(22 \%)$ of A1 and $9(21 \%)$ A2 subject's samples. Compliance between $\mathrm{A} 1$ and $\mathrm{A} 2$ subjects was not different. Amantadine concentration was measured specifically at trough (22-26 hours after a dose) in $13(30 \%), 16$ $(36 \%)$, and $5(17 \%)$ of $\mathrm{Al}, \mathrm{A} 2$ and $\mathrm{AP}$ subjects respectively. Mean concentrations of amantadine, at trough, were $146 \pm 33$ $\mathrm{ng} / \mathrm{ml}($ mean $\pm \mathrm{SE}$ ) and $244 \pm 26 \mathrm{ng} / \mathrm{ml}$ in the $\mathrm{Al}$ and $\mathrm{A} 2$ groups respectively but the difference did not attain statistical signif icance (Mann-Whitney U test, $0.05<P<0.10$ ).

Overall, compliance in all A1 plus A2 subjects was $84 \%$ $(150 / 178)$ and was not different between $1980-81$ and $1982-$ 83. There was no difference between $A 1$ and $A 2$ groups in the two study periods or between $\mathrm{Al}$ and $\mathrm{A} 2$ groups in both years.

Adverse Effects. Completed questionnaires were returned by $64 \%$ of $V$ recipients in $1980-81,74 \%$ in $1981-82$ and $98 \%$ in $1982-83(\mathrm{P}<0.01$ for $1982-83$ compared to either previous year). The same trend was observed for VP recipients: $82 \%$ in $1980-81,87 \%$ in $1981-82$, and $100 \%$ in $1982-83$. The percentages were higher in the last year than in both previous years for both V \& VP groups ( $P<0.05$ ). Only $32 \%$ of $V$ recipients and $46 \%$ of VP recipients returned completed forms after the second injection in 1981-82.

No one missed work in the 10 days after immunization.

No differences in the proportions of $V$ and VP subjects reporting any symptom were observed in 1980-81, when vaccine containing $7 \mu \mathrm{g}$ of $\mathrm{HA}$ per vaccine virus was administered. However, in both 1981-82 and 1982-83, higher proportions of $\mathrm{V}$ recipients immunized with vaccine containing $15 \mu \mathrm{g} \mathrm{HA}$ per vaccine virus, complained of sore muscles at the deltoid injection site, than did VP recipients. The proportions (percentages) were $22 / 56$ (39\%) for V compared to $3 / 42(7 \%)$ for $\mathrm{VP}(\mathrm{P}<0.05)$ and $18 / 63(29 \%)$ for $\mathrm{V}$ compared to $2 / 38(5 \%)$ for VP $(P<0.01)$ in the two study periods respectively. Vaccine with $15 \mu \mathrm{g}$ HA did not cause myalgia more commonly than that with $7 \mu \mathrm{g} \mathrm{HA}$. There were no other differences between proportions of $\mathrm{V}$ and VP recipients citing adverse symptoms.

Ninety-eight to $100 \%$ of subjects in the three chemoprophylaxis groups returned the completed first questionnaires in 1982-83 which was more than in 1980-81 (61-81\%). The same difference was observed for the second questionnaire: $76-85 \%$ in $1982-83$ and $58-64 \%$ in $1980-81$. The only amantadine-related difference in adverse symptom was abdominal pain which was reported by $9 / 38$ A2 subjects compared to $1 / 39$ AP respondents in 1980-81 ( $\mathrm{P}<0.01)$. No significant differences were observed in any symptoms reported during the first 10 days of capsule ingestion as compared to days 22 to 32 of capsule ingestion at the same dose.

\section{Discussion}

We were unable to compare the efficacy of influenza vaccine or amantadine for preventing influenza A illness in Canadian
Forces volunteers in this study because the clinical attack rates in our study population were too low. Although the proportion of subjects in our study susceptible to strains of influenza A virus in the vaccine declined over the three years of the study, this would not have precluded a rigorous test of the hypothesis if a new antigenic strain had emerged and caused epidemic illness.

The potential of these two strategies for preventing influenza was estimated from data on the acceptability of vaccine and amantadine. The acceptibility of vaccine was evaluated by its immunogenicity and side-effects. Vaccine-induced protection was assessed by measuring serum HAI responses since titres of $>20$ for homologous virus are considered protective ${ }^{13}$ although the relationship is not absolute..$^{14.15}$ Of all immunized subjects, $89 \%$ had HAI titres $>20$ for all 3 vaccine HA. That is, these data suggested that up to $11 \%$ of immunized subjects would not have been protected against vaccine strains of influenza A virus. If serum HAI titres of $>40$ were needed to ensure protection, then up to $67 \%$ of these subjects would not have been protected. These HAI data are virtually identical to those reported for the same vaccine in United States Air Force recruits in whom $91-95 \%$ of subjects had HAI titres $>16$ three weeks after immunization. ${ }^{16}$

Study data illuminated other aspects of the HAI response to vaccine. The HAI antibody response to $7 \mu \mathrm{g}$ versus $15 \mu \mathrm{g} \mathrm{HA}$ of $A /$ Bangkok/1/79 was not different in individuals with no detectable homologous HAI antibody. In individuals with preexisting homologous antibody, influenza A/Bangkok/1/79 (H3N2) (15 $\mu \mathrm{g} \mathrm{HA}$ ) was a more potent immunogen than $\mathrm{A} /$ Brazil/11/78 (H1N1) (and B/Singapore/222/79). Protective antibody titres of $>20$ persisted for at least 5 months.

Side-effects to vaccine were relatively minor. Myalgia at the site of injection was the commonest adverse effect of vaccination. It occurred in up to $48 \%$ of vaccine recipients over the three years, compared to as many as $24 \%$ of subjects receiving saline. This seemed an acceptable level of side-effects if one deducted the placebo response and considered the lack of an increase in absenteeism in the 10 days after ingestion. This conclusion accords with observations in large-scale placebo trials in which "local reactions rarely presented significant problems to the recipients". ${ }^{17}$ Vaccine related side-effects were independent of HA content over the range studied. Failure of up to $36 \%$ of vaccine recipients to return questionnaires may have biased these interpretations. However, it is more likely that failure to reply signified lack of adverse effects rather than their occurrences. Thus, overall, influenza vaccine-induced HAI antibody was potentially protective in a high percentage of subjects with little associated morbidity from sideeffects.

The potential utility of amantadine chemoprophylaxis could similarly be estimated from tolerance data during 32 and 39 consecutive days of ingestion, and compliance. Tolerance of 100 and $200 \mathrm{mg}$ per day was high compared to the matching placebo and no dose-related adverse effects could be demonstrated. This interpretation was further supported by the lack of difference in drop-out ratio between the placebo and amantadine groups. We suspected that the need to ingest capsules per se caused dropouts because all volunteers allocated to chemoprophylaxis groups but never given capsules concluded 
the study in 1981-82. Individuals who had amantadine in plasma appeared to be ingesting their doses precisely as recommended. This interpretation is supported by the observation that the mean steady-state trough amantadine concentration in A2 subjects was almost double that observed in A1 recipients, 244 and $146 \mathrm{ng} / \mathrm{ml}$ respectively. Moreover, these plasma concentrations were very similar to those expected from the regression of trough steady-state plasma concentration on dose in similar volunteers ingesting 50 to $300 \mathrm{mg} /$ day. ${ }^{5}$ The same cannot be inferred in respect of the assiduousness of amantadine ingestion by subjects in 1980-81, from urine amantadine measurements, even though the mean concentration of amantadine in subjects ingesting $200 \mathrm{mg} /$ day was 3 times greater than in those ingesting $100 \mathrm{mg} / \mathrm{day}$. This follows from observations that amantadine elimination through the kidneys is effected by both glomerular filtration and probably tubular secretion $^{18}$ and is affected by glomerular filtration rates and the $\mathrm{pH}$ of urine. ${ }^{19}$

Overall, chemoprophylaxis was potentially protective in $84 \%$ of these subjects. An attempt to assess compliance in another long-term influenza A chemoprophylaxis trials was reported by Dolin et $\mathrm{al}^{6}$ who measured amantadine in urine from a random sample of $9(6 \%)$ of 145 amantadine recipients ingesting drug for 6 weeks. Although the time of sampling during the 6 weeks is not specified, 8 of 9 subjects had amantadine detectable in urine $(52-438 \mu \mathrm{g} / \mathrm{ml})$. This is a level of compliance $(89 \%)$ similar to that which we observed. Whether protection of up to $84 \%$ of a population would protect members not ingesting drug by virtue of 'herd immunity' is unknown.

Acute respiratory tract infections occurred in $6-28 \%$ of volunteers during the three study periods. The majority of illnesses, 50-59\% were common colds, an incidence of 155 / 1000 persons. This is considerably less than the frequency of $2-4 /$ person/season in civilians and up to $12 /$ person/year in new military recruits. ${ }^{20.21}$ No reasons for these differences were evident. Interestingly, influenza-like illnesses accounted for $21-32 \%$ of the illnesses. Aetiologic diagnoses were established in $34 \%$ of all ill subjects; a virus was isolated only from 2 ill subjects $(1.4 \%)$. Coronaviruses caused $52 \%$ of the colds and $60 \%$ of the cases of pharyngitis in which an agent was identified. Hendley et al have described such illnesses caused by coronaviruses in military recruits. ${ }^{22}$ Surprisingly, in 29 subjects with influenza-like illness, an influenza virus aetiology was only demonstrated in 1 by virus isolation. Coronaviruses were implicated in 8 cases. Although coronaviruses have been demonstrated to cause pneumonia and pleural reactions as well as severe colds with systemic symptoms such as malaise, headache, and chills, an influenza-like illness has not been described. ${ }^{23}$ Dual-infections in which serologic data indicating infection with a coronavirus plus one or more other pathogens occurred in 3 of the 25 subjects with coronavirus infection. Such dual infection involving coronavirus has been previously described ${ }^{24}$ However only one of the dual infections occurred in individuals with influenza-like illnesses suggesting that dual infection did not account for the association of coronavirus with this type of acute illness.

In conclusion, these data provide no basis for recommending either a vaccine-or chemoprophylaxis-based strategy for preventing influenza A illness in Canadian Forces personnel but they suggest that both strategies could be potentially highly acceptable. The difficulty of knowing whether data on influenza $A$ attack rates in the surrounding community are relevant to personnel on Canadian Forces Bases has been illustrated. Perhaps, as was originally suggested by Dr. George G. Jackson, ${ }^{25}$ these two modalities for controlling influenza should be seen as complementary, with vaccine used as the primary preventive measure and amantadine employed when vaccine is not available or rendered potentially ineffective by an antigenic shift in a new influenza A strain.

\section{Acknowledgments}

We thank our volunteers, the Directorate of Preventive Medicine. Department of National Defence and the Base Commanders, Surgeons, and Medical Officers at CFB's Winnipeg, Shilo, Portage, and $2^{\text {nd }}$ PPCLI Winnipeg, Dr. David A.J. Tyrrell, Salisbury, U.K., and our technicians.

\section{References}

1. Glezen WP: Serious morbidity and mortality associated with influenza epidemics. Epidemiologic Reviews 4:25-44, 1982

2. Davenport FM: Influenza viruses in: Viral infections of humans. Epidemiology and Control, AS Evans (Ed.). New York, Plenum Press, 1982

3. Hoffman $\mathrm{CE}$ : Amantadine $\mathrm{HCl}$ and related compounds. In: Selective inhibitors of viral functions. WA Carter(Ed.). Cleveland, Ohio, CRC Press, 1973

4. Smorodintsev AA, Karpuchin GI, Zlydnikov DM, et al: The prospect of amantadine for prevention of influenza $A 2$ in humans (effectiveness of amantadine during influenza A2/Hong Kong epidemics in January-February, 1969 in Leningrad). Ann NY Acad Sci 173:44-61, 1970

5. Aoki FY, Stiver HG, Sitar DS, et al: Prophylactic amantadine dose and plasma concentration-effect relationships in healthy adults. Clin Pharmacol Ther 37:128-136, 1985

6. Dolin R, Reichman RC, Madore HP, et al: A controlled trial of amantadine and rimantadine in the prophylaxis of influenza $\mathrm{A}$ infection. $\mathrm{N}$ Engl $\mathrm{J}$ Med 307:580-583, 1982

7. Galbraith AW, Oxford JS, Schild GC, et al: Protective effect of 1-amantadanamine hydrochloride on influenza A2 infections in the family environment. A controlled double-blind study. Lancet ii:1026-1028, 1969

8. Biandrate $P$. Tognoni $G$, Belvedere $G$, et al: A gas chromatographic method for the determination of amantadine in human plasma. J Chromatogr $74: 31-34,1972$

9. United States Department of Health, Education and Welfare. Advanced laboratory techniques for influenza diagnosis. Immunology series ${ }^{*} 6$. Centers for Disease Control. Atlanta, 1975

10. Kraaijeveld GA, Madge MH. MacNaughton MR.: Enzyme-linked immunosorbed assay for coronavirus HCV 229E and MH43. J Gen Virol 49:8389,1980

11. Anonymous. Influenza in Canada (Report). Can Dis Weekly Rep 7:5, 1981

12. Bollegraaf E: Influenza - Canada. Can Dis Weekly Rep 9:9, 1983

13. Salk J, Salk D: Control of influenza and poliomyelitis with killed virus vaccines. Science 195:834-845, 1977

14. Morris JA, Kasel JA, Saglan M, et al: Immunity to influenza is related to antibody level. N Engl J Med 274:527-535, 1966

15. Foy HM, Allan I, Blumhagen JM, et al: A/USSR and B/Hong Kong vaccine: Field experiences during an $A / B r a z i l$ and an influenza $B$ epidemic. J Amer Med Assoc 245:1736-1740, 1981

16. Gremillon $\mathrm{DH}$, Meiklejohn G, Graves $P$, et al: Efficacy of single-dose influenza immunization in Air Force recruits. J Infect Dis 147:1099, 1983

17. Parkman PD, Galasso GJ, Noble GR: Summary of clinical trials of influenza vaccines. J Infect Dis 134:100-107, 1976 
18. Aoki FY, Sitar DS, Ogilvie RI: Amantadine kinetics in healthy young subjects after long-term dosing. Clin Pharmacol Ther 26:729-736, 1979

19. Geuens HF, Stephens RL: Influence of the $\mathrm{pH}$ of the urine on the rate of excretion of 1-adamantanamine. Fifth International Congress Chemotherapy, Vienna, Austria, June 26-July 1, 1967, p. 703-713

20. Gwaltney JM Jr, Hendley JO. Simon G: Rhinovirus infections in an industrial population. I. The occurrence of illness. N Engl J Med 275:1261-68, 1966

21. Rosenbaum MJ, DeBerry P, Sullivan LSJ, et al: Epidemiology of the common cold in military recruits with emphasis on infections by rhinovirus types 1A, 2A, and two unclassified rhinoviruses. Am J Epidemiol 93:183-93, 1971
22. Hendley JO, Fishburne HB. Gwaltney JM Jr: Cornavirus infections in working adults. Eight-year study with $229 \mathrm{E}$ and OC43. Amer Rev Resp Dis 105:805-11, 1971

23. McIntosh K: Coronavirus: In: Principles and Practice of Infectious Diseases. Mandell GL, Douglas RG Jr, Bennett JE (Eds). New York, John Wiley \& Sons, $2^{\text {nd }}$ Edition, p. 893-897, 1985

24. Wenzel RP. Hendley JO, Davies JA, et al: Coronavirus infections in military recruits. Three year study with coronavirus strains OC43 and 229E. Amer Rev Resp Dis 109:621-24, 1974

25. Jackson JG, Stanley ED: Prevention and control of influenza by chemoprophylaxis and chemotherapy. J Am Med Assoc 235:2739-41, 1976

\section{Book Reviews}

EMERGENCY MEDICINE: SELF-ASSESSMENT AND REVIEW. Harold A. Thomas, Jr., M.D., John Koehler, M.D., and Robert E. O'Connor, M.D. The C.V. Mosby Company.

This text represents another in a series of aids geared at improving the students knowledge base of Emergency Medicine. It consists of several hundred multiple choice questions covering several aspects of Emergency Medicine. The editor's point out that the percentage of questions covered in each subject is the same as that in the American Board of Emergency Medicine written exam. This group of test questions is keyed to the text by Rosen et al entitled "Emergency Medicine: Concepts and Clinical Practice," which is an excellent clinical text. Having recently completed the American Board of Emergency Medicine exam, I found this text to be relevant in scope and difficulty. A review of several questions yielded good correlation with the text and few ambigious questions. This is a reasonable and useful tool for those who desire this form of learning aid.

GEORGES C. BENJAMIN, M.D., F.A.C.P. MAJ, MC

GUIDELINES FOR EXERCISE TESTING AND PRESCRIPTION. American College of Sport Medicine, written by the Preventive and Rehabilitative Exercise Committee of American College of Sports Medicine, Steven N. Blair P.E.D., Chair. Lea and Fibiger Philadelphia, PA. 3rd ed., 1986, 179 pages, no illustrations, no price available.

This is the 3rd edition which has been extensively revised. Two new chapters have been added dealing with exercise for special patient populations, patients with hypertension angina, obesity, and principles of behavioral medicine to initate and maintain a healthy life style. The book gives guidelines for the health care provider for evaluation of health status, prior to exercise testing and prescription. Principles of exercise prescription to include prescription for cardiac patients including inpatient programs, outpatients and community exercise programs. This is a useful book for the health care practitioner involved with exercise prescription.

$$
\text { ANGELO SCAVARDA, M.D. COL, MC }
$$

SURGICAL DIAGNOSIS AND MANAGEMENT. David C. Dunn, MB, MChir, FRCS, Addenbrooke's Hospital, Cambridge, Associate Lecturer, University of Cambridge, School of Clinical Medicine, Director of Medical Studies, St. John's College, Cambridge Nigel Rawlinson, MB, BChir, Formerly Anatomy Demonstrator, Department of Anatomy, University of Cambridge. Blackwell Scientific Publica- tions, Oxford, London, Edinburgh, Boston, Palo Alto, S.S. Melbourne, $1985,610 \mathrm{pp}$., 106 illus.

The authors state that the stimulus to produce this book was the repeated demands of medical students and house officers for a concise practical text listing methods of diagnosis and management of main general surgical conditions. The authors have provided them with a review of twelve major areas of challenge in general surgery. Rapid reference is possible by utilizing the Contents at the beginning of the book and the brief outline at the beginning of each subchapter. Although deficiencies can be identified, this outline from a major medical center in England can be a valuable reference source for any student/house officer in surgical training.

NORMAN M. RICH, M.D., F.A.C.S.

HEMOSTASIS: A CASE ORIENTED APPROACH. Douglas A. Triplett, M.D., Professor of Pathology and Assistant Dean, Indiana University School of Medicine, Director, Muncie Center for Medical Education, and Director of Hematology, Ball Memorial Hospital, Muncie, Indiana.

Published by IGAKU-SHOIN Medical Publishers, Inc., 1140 Avenue of Americas, New York, N.Y. 10036, 1985, 321 pages, 123 illus, $\$ 29.50$.

This book is written for students, technologists, and physicians who wish to learn more about coagulation through evaluation of individual patients with disorders of hemostasis. The book is divided into two parts. In the first part the author reviews in four chapters the biochemistry of blood coagulation, fibrinolysis, the roles of platelets and endothelial cells in coagulation, and the clinical and laboratory approach to bleeding disorders. The second part is comprised of sixty-two case histories that are organized under the categories of hereditary and acquired disorders of coagulation proteins and physiologic inhibitors, hereditary and acquired disorders of platelets, and complications associated with anticoagulant therapy. The index provides a quick guide to specific examples of each coagulation disorder. Many topics are covered in a somewhat superficial fashion; however numerous texts are available to provide detailed information about specific areas of interest. The book is an excellent guide for instructors and for those who wish to learn more about a practical approach to disorders of hemostasis.

Barbara M. Alving, M.D., LTC MC

Continued on page 472 